\title{
Effectiveness of Monetary Policy Transmission Mechanism in an Implicit Inflation Targeting Regime: The Case of Nigeria.
}

\section{Anthony Enisan Akinlo}

Qbafemi Awolowo University, Faculty of Social Sciences

Olumuyiwa Tolulope Apanisile ( $\square$ mapanisile@gmail.com )

Obafemi Awolowo University Faculty of Social Sciences

\section{Research Article}

Keywords: Transmission Mechanism, Monetary Policy, DSGE, Inflation Targeting, Monetary Aggregates

Posted Date: April 30th, 2021

DOl: https://doi.org/10.21203/rs.3.rs-317014/v1

License: (c) (1) This work is licensed under a Creative Commons Attribution 4.0 International License.

Read Full License 


\title{
Effectiveness of Monetary Policy Transmission Mechanism in an Implicit Inflation Targeting Regime: The Case of Nigeria.
}

\begin{abstract}
The study examines the effectiveness of the monetary policy transmission mechanism in Nigeria by estimating a sticky-price DSGE model using the Bayesian estimation approach. This study is important given the implicit inflation targeting framework employed in the implementation of monetary policy in the country. The study employs quarterly data from 2000:1 to 2019:4 to estimate the two main categories of monetary policy frameworks, monetary aggregate and implicit inflation targeting, respectively. Data are sourced from World Development Indicator (online version). Empirical results show that the monetary policy transmission channels are effective in transmitting policy impulses to the economy within this regime. However, the monetary aggregate framework that is made explicit dampens the achievement of this framework. The study, therefore, concludes that inflation targeting should be made explicit in the country in other to reap the benefits embedded in the framework.
\end{abstract}

Keywords: Transmission Mechanism, Monetary Policy, DSGE, Inflation

Targeting, Monetary Aggregates

JEL Classification: C68, E58, E12 


\section{Introduction}

The pursuance of price stability is a major goal of monetary policy in all economies irrespective of their level of development. As a result, monetary policy is often designed to influence the attainment of this objective. Over the years, monetary policy has been undertaken out under different regimes. However, each regime has been operated adopting different frameworks which affect the operating, intermediate, and the ultimate targets. The monetary policy framework refers to the strategy monetary authority adopts in achieving its objectives. Central banks worldwide take into cognisance the continuous assessment and evaluation of policy framework as it gives room for adjustment to the changing structure and economic situation of each country. In recent years, the commonly used monetary policy regimes are monetary targeting and inflation targeting.

Monetary targeting involves targeting the growth of the money supply as a way of controlling inflation. The effectiveness of this approach depends on the extent to which central bank of a country can control money supply and how money growth is stably related to inflation. Shreds of evidence have shown that the use of monetary targeting recorded little success because the demand for money became unstable due to recent developments in the financial sector. Therefore, many countries embraced the use of inflation targeting. Inflation targeting entails the central bank committing to the conduct of monetary policy to achieve a publicly announced inflation target within a specified time. The regime uses interest rate as the policy instrument to bring inflation within the bound. Inflation targeting provides a rule-like framework within which the central bank has the discretion to react to shocks. The beauty of this approach is that it combines elements of both rules and discretion in monetary policy. Inflation targeting could be explicit or implicit. It is explicit when the traditional interest rate is the only policy instrument, thereby making the interest rate channel more pronounced above all other monetary channels. In contrast, it is implicit when the interest rate is combined with another policy instrument and interest rate channel is not pronounced (Can, Bocuoglu \& Can, 2020). New Zealand was the first country to adopt an inflation targeting regime in 1990. Several other countries embraced the policy afterwards. For instance, Canada started the policy in 1991, followed by the United Kingdom, Australia, and South Africa in 1992, 1993 and 2000 respectively. Also, the Central Bank of Turkey introduced implicit inflation targeting in 2002 but later implemented full-fledge inflation targeting in 2006 (Akyurek, Kutan \& Yilmazkuday, 2011).

Nigeria also adopted an inflation targeting regime in the year 2000. The country adopted this policy due to the failure of monetary targeting to stabilize the demand for money function. The instability of the demand for money function had an adverse effect on the relationship between money and prices. In particular, it complicated the demand for money forecast in the country, hence the switch. The goal of this monetary policy is to maintain the inflation rate within the target of between 6 - 9 percent (CBN, 2017). Nigeria adopted the implicit inflation targeting approach. Thus, the implementation of monetary policy in Nigeria follows both monetary targeting framework where the money supply is the policy instrument and a rulelike framework where the interest rate is the policy instrument. In this case, monetary targeting is explicit, while inflation targeting is implicit. Besides, the traditional interest rate channel is not pronounced. This approach is similar to Turkey's implicit inflation targeting of 2002. However, while Turkey experienced tremendous achievement in disinflation and policy environment, which led to the adoption of full-fledged inflation targeting in 2006; Nigeria's experience is different. Since the inception of inflation targeting in Nigeria, evidence has shown that inflation targeting arrangement still displays less achievement in keeping inflation within the target range. For instance, the inflation rate increased from 6.9 percent in 2000 to 
18.87 percent in 2001. The figure decelerated to 17.86 percents in 2005 . In 2012, the inflation rate in the country further declined to 12.21 percent. The figure rose to 16.52 in 2017. As of 2019, the inflation rate was 11.39 (CBN 2019). The wide gap between actual rate and the target bound casts serious doubts on the effectiveness of the inflation targeting monetary policy framework in Nigeria.

Akyurek et al. (2011) argued that effective transmission mechanism is necessary for the inflation targeting framework to achieve its objectives. According to them, effective channel of transmission is necessary to achieve further gains in disinflation and maintain price stability. Basically, the stronger the transmission channels and the better they are understood, the more effective the inflation targeting framework in achieving lower levels of inflation. Given the inability of the inflation targeting framework in Nigeria to achieve its objectives, it is imperative to examine the effectiveness of monetary policy transmission channels. Therefore, the purpose of this study is to investigate the effectiveness of monetary policy transmission channels in Nigeria under implicit inflation targeting regime using Dynamic Stochastic General Equilibrium (DSGE). The choice of DSGE is informed by its numerous advantages in policy analysis over other techniques (Peiris and Saxegaard, 2007; Akinlo and Apanisile, 2018; Apanisile and Osinubi, 2020).

The rest of the paper is structured as follows: section 2 examines the extant literature on the effectiveness of the monetary policy transmission channels. Section 3 explains the methodological issues about DSGE as used in this study. Estimation of the models is implemented in section 4 . Section 5 presents the findings and discusses their implications on the workings of inflation targeting in Nigeria. Section 6 concludes.

\section{Review of Extant Literature}

The importance of effective monetary policy transmission channels to the conduct of monetary policy cannot be overemphasized. The understanding of how fast and the extent to which monetary policy impulses are transmitted to the economy gives Central Banks insight for better decision-making. Several studies have examined this subject matter in the literature, and they concluded that the effectiveness of transmission channels varies under different conditions. For instance, Cevik and Teksoz (2013) examined the effectiveness of the monetary policy transmission channels in the Gulf Cooperation Council (GCC) countries using a Structural Vector Autoregressive model between 1990 and 2010. The results showed that interest rate and bank lending channels were effective in influencing output and prices. Fuddin (2014) discussed the effectiveness of the monetary transmission mechanism of monetary policy in Indonesia in the face of financial globalisation and structural changes. The study employed Vector Error Correction Model between 1961 and 2011. Results showed that credit channel was effective in influencing output, while the interest rate was the most active channel in controlling inflation. In the same vein, Ripidian, Hayati, and Yusuf (2018) analysed the monetary mechanism effectiveness in managing inflation in Indonesia, given structural changes in the financial and banking sector using Vector Error Correction Model between 2005:1 and 2016:4. The study found that the expectation channel was the most active in controlling inflation during the period.

In another study conducted in Asia using eight emerging Asian economies, Jain-Chandra and Unsal (2014) employed the Generalised Dynamic Factor Model and Structural Vector Autoregression Model to investigate how large capital inflows affect the effectiveness of 
monetary policy transmission channels in open economies between 2000 and 2010. Results showed that though the transmission mechanism was effective during the period under study as it worked through short-term interest rates; however, it was weaker during the periods of increase in capital inflows. Amar, Hachicha, Saadallah (2015) empirically investigated the effectiveness of the monetary transmission mechanisms in Saudi Arabia, where Islamic banking is in vogue. The study employed Structural VAR to analyze quarterly data between 1990 and 2013. The results showed that bank lending channel was relatively effective in influencing non-oil private output but less effective in influencing inflation. Awad (2011) investigated the effectiveness of monetary policy transmission channels in Egypt taking into consideration the susceptibility of the economy to external shocks. The study employed Structural VAR to analyse quarterly data for the period 1995:1 and 2007:4. The results showed that interest rate was the dominant channel in the country. Patrick and Akanbi (2017) examined the relative effectiveness of monetary transmission mechanisms in Zambia during inflation targeting regime using VAR and monthly data spanning between January 1993 and June 2015. The results showed that exchange rate and credit channels were the effective channels of monetary policy in the country. In Ukraine, Zholud, Lepushynskyi and Nikolaychuk (2019) analysed the effectiveness of the monetary transmission mechanisms after the Central Bank of Ukraine transition to inflation targeting regime. The study found the exchange rate channel as most active channel of monetary transmission in the country. The interest rate channel was weak because of slow post-crisis recovery.

In Nigeria, Ogun and Akinlo (2010) discussed the effectiveness of the monetary policy transmission channels with emphasis on the significance of the bank-credit channel given the adoption of deregulatory measures in the country. The study employed structural VAR with quarterly data spanning between Q1 of 1986 and Q4 of 2006. The study found that the bankcredit channel was ineffective during the period under review. Moreover, Otolorin and Akpan (2017) assessed the effectiveness of the monetary transmission mechanisms in achieving low inflation during the period of recession using VAR. The study employed secondary data spanning from 1981 to 2015. The results showed that interest rate was effective in controlling inflation but not output. To assess the effectiveness of monetary policy in the face of internal and external shocks, Akinlo and Apanisile (2019) decomposed total shocks into anticipated and unanticipated shocks. Four transmission channels were considered due to the economic and financial conditions of the country. The data spanned between 1986:1 and 2013:4. The DSGE results showed that unanticipated shock had short-run impacts on the transmission mechanism while anticipated had long-run impacts. Also, Apanisile and Osinubi (2020) examined the effectiveness of the monetary transmission mechanisms in the face of financial sector development in Nigeria between 2004:1 and 2016:4; by estimating the sticky-price DSGE model using a Bayesian approach. The results showed that the credit channel was the most active in stimulating output, while expectation channel was the most active channel in stabilising prices.

In conclusion, the review confirms the existence of several studies on the subject matter in the literature. Although studies have assessed the effectiveness of monetary policy transmission channels under different conditions, the performance of monetary transmission channels under implicit inflation targeting regime is missing in the literature, particularly in Nigerian. Besides, most studies on the subject matter in Nigeria employed only structural VAR. To address these gaps in the case of Nigeria, this study examines the effectiveness of the monetary policy transmission mechanisms under implicit inflation targeting framework using DSGE methodology based on its superiority over SVAR.

\section{Methodology}


The New Keynesian model extends the neoclassical Real Business Cycle setup by introducing Keynesian features like imperfect competition and sticky prices. Hence, it provides a setting that allows monetary policy to be central to macroeconomic fluctuations. One of the basic assumptions of the model is imperfect competition in the goods market. It also assumes that firms produce branded goods for which they set their prices. Furthermore, the workings of the model is based on sticky-prices, which implies that only a fraction of firms can reset their prices in any given period. Key players of the New Keynesian Model are households that make consumption and labour supply decisions, demand money and bonds, firms that demand labour to produce goods and services, and government that runs monetary policy.

\subsection{Household}

The model assumes a set of identical, infinitely-lived households that seek to maximize utility:

$$
\max _{C_{t}, N_{t}, \frac{M_{t}}{P_{t}}} E_{0} \sum_{t=0}^{\infty} \beta^{t} U\left(C_{t}, N_{t}, \frac{M_{t}}{P_{t}}\right)
$$

Where $E_{0}$ denotes expectation operator condition on time 0 information; $\beta$ is the discount factor, $\frac{M_{t}}{P_{t}}$ is the real money holding; subject to the budget constraint:

$$
P_{t} C_{t}+Q_{t} B_{t}+M_{t} \leq+M_{t-1} B_{t-1}+W_{t} N_{t}+J_{t}
$$

Where $C_{t}(i)$ represents the quantity of good $i$ consumed by the household in period $\mathrm{t}$, for $i \in$ $[0,1]$ for $\mathrm{t}=0,1,2, \ldots, P_{t}(i)$ is the price of good $i, N_{t}$ denotes hours of work, $W_{t}$ is the nominal wage, $B_{t}$ represents purchases of one period bonds at price $Q_{t}, B_{t-1}$ is the number of bonds purchased last year, $M_{t}$ is money holding and $J_{t}$ is a lump-sum component of income. $\epsilon$ measures the intratemporal elasticity of substitution between the differentiated goods , which is equal to the price elasticity of demand. Using Kuhn-Tucker approach to obtain FOC conditions of equations (1) and (2) and re-arrange, we have:

$$
\begin{array}{r}
1=\beta\left(1+i_{t}\right) E_{t}\left\{\frac{U_{c(t+1)}}{U_{c(t)}} \frac{P_{t}}{P_{t+1}}\right\} \\
-\frac{U_{N(t)}}{U_{C(t)}}=\frac{W_{t}}{P_{t}} \\
\frac{U_{M(t)}}{U_{C(t)}}=\frac{i_{t}}{1+i_{t}}
\end{array}
$$

Equations (3), (4) and (5) determine the intertemporal consumption allocation (the Euler equation), the labour-leisure choice, and the money demand, respectively. The equations determine the rational forward-looking household's allocation decision. 
Under the assumption of a period utility given by:

$$
\mathrm{u}\left(C_{t}, N_{t}, M_{t}\right)=\frac{C_{t}^{1-\sigma}}{1-\sigma}-\frac{N_{t}^{1+\varphi}}{1+\varphi}+\frac{\left(\frac{M_{t}}{P_{t}}\right)^{1-v}}{1-v}
$$

The marginal utilities of consumption, labour, and money become:

$$
\begin{gathered}
U_{C t}=C_{t}^{-\sigma} \\
U_{N t}=-N_{t}^{\varphi} \\
U_{M t}=\left(\frac{M_{t}}{P_{t}}\right)^{-v}
\end{gathered}
$$

Substituting the marginal utilities into equations (3) - (5), we have:

$$
\begin{gathered}
1=\beta Q_{t}^{-1} E_{t}\left\{\left(\frac{C_{t+1}}{C_{t}}\right)^{-\sigma} \frac{P_{t}}{P_{t+1}}\right\} \\
C_{t}^{\sigma} N_{t}^{\varphi}=\frac{W_{t}}{P_{t}} \\
\frac{M_{t}}{P_{t}}=C_{t}^{\frac{\sigma}{v}}\left(\frac{1+i_{t}}{i_{t}}\right)^{\frac{1}{v}}
\end{gathered}
$$

Log- linearize equations (7) - (9) and denote log of variables in capital letter with small letters, we have:

$$
\begin{aligned}
& c_{t}=E_{t} c_{t+1}-\frac{1}{\sigma}\left(i_{t}-\rho-E_{t} \pi_{t+1}\right) \\
& w_{t}-p_{t}=\sigma c_{t}+\varphi n_{t} \\
& m_{t}-p_{t}=c_{t}-\eta i_{t}
\end{aligned}
$$

\subsection{Firms}

The model also assumes a set of firms indexed by $i \in[0,1]$. Each firm produces a differentiated good, but they all use identical technology, represented by the production function:

$$
Y_{i t}=A_{t} N_{i t}^{1-\alpha}
$$

$Y_{i t}$ is the output produced by firm $i$ in period $t, A_{t}$ is the economy-wide technology level, and $N_{i t}$ is labour force used by the firm. One key ingredient in the New Keynesian model is price 
rigidity. When firm sets their prices, they can do so freely. However, they do not know when the next opportunity to change price will emerge. Therefore, the probability of not knowing when to change price in a given period is $\theta$. This is the fraction of all firms stuck with the price they had last period, while the remaining $1-\theta$ firms reset their prices. All firms face an identical elastic demand schedule with price elasticity $\epsilon$ and take aggregate price level $P_{t}$ and aggregate consumption index $C_{t}$ as given. Also, the aggregate price dynamics are described by the equation:

$$
\pi_{t}^{1-\epsilon}=\theta+(1-\theta)\left(\frac{P_{t}^{*}}{P_{t-1}}\right)^{1-\epsilon}
$$

Where:

$\pi_{t} \equiv \frac{P_{t}}{P_{t-1}}$ is the gross inflation rate, and $P_{t}{ }^{*}$ is the price set in the period t by firms that are re-optimizing their price in that period. Since all firms will choose the same price because they face an identical problem, the steady-state with zero-inflation will give $\pi=1$. In that case, $P_{t}{ }^{*}=P_{t-1}=P_{t}$. Therefore, a log-linear approximation to the aggregate price index around zero inflation steady state gives:

$$
\pi_{t}=(1-\theta)\left(P_{t}^{*}-P_{t-1}\right)
$$

Equation (15) above shows that inflation in the present period is as a result of re-optimizing firms that choose the price that is different from the economy's average price in the previous period. Hence, to understand the evolution of inflation over time, there is a need to analyze the factors underlying firms' price-setting decisions. This is done by considering a firm reoptimizing in period $\mathrm{t}$ that chooses a price $P_{t}{ }^{*}$ that maximizes the current market value of the profits generated while the price remains effective. The optimization problem is solved as follows:

$$
\max _{t}{ }^{*} \sum_{k=0}^{\infty} \theta^{k} E_{t}\left[Q_{t, t+k}\left(P_{t}^{*} Y_{t+k / t}-\varphi_{t+k}\left(Y_{t+k / t}\right)\right)\right]
$$

Subject to the sequence of demand constraints:

$$
Y_{t+k / t}=\left(\frac{P_{t}^{*}}{P_{t+k}}\right)^{-\epsilon} C_{t+k}
$$

The first order condition of the problem takes the form:

$$
\sum_{k=0}^{\infty} \theta^{k} E_{t}\left(Q_{t . t+k} Y_{t+k / t}\left[P_{t}^{*}-M \omega_{t+k / t}\right]\right)=0
$$


for $\mathrm{k}=0,1,2, \ldots \ldots$.. where $Q_{t, t+k}$ is the stochastic discount factor for nominal payoffs, $\varphi_{t}($. is the cost function and $Y_{t+k / t}$ denotes output in period $\mathrm{t}+\mathrm{k}$ for a firm that last reset its price in period $\mathrm{t}, \theta^{k}$ is the probability of being stuck with today's price in $\mathrm{K}$ periods and $\mathrm{M}$ is the desired or frictionless mark-up. The optimal price $P_{t}^{*}$ becomes:

$$
p_{t}^{*}=\mu+(1-\theta \beta) E_{t} \sum_{k=0}^{\infty} \theta^{k} \beta^{k}\left[m r_{t+k \mid t}^{r}+p_{t+k}\right]
$$

To solve for equilibrium in the goods market, the market clearing condition requires that:

$$
Y_{i t}=C_{i t}
$$

Aggregate output in the market is defined as:

$$
Y_{t}=\left(\int_{0}^{1} Y_{i t}^{\frac{\epsilon-1}{\epsilon}} d i\right)^{\frac{\epsilon-1}{\epsilon}}
$$

Substitute for (20) in (21), equation (21) then becomes:

$$
Y_{t}=C_{t}
$$

Taking $\log$ of both sides, we have:

$$
y_{t}=c_{t}
$$

Equation (22) is the aggregate market clearing condition. Besides, market clearing in the labour market equals:

$$
N_{t}=\int_{0}^{1} N_{i t} d i
$$

Re-arrange (13) by making $N_{i t}$ the subject. Equation (13) becomes

$$
N_{i t}=\left(\frac{Y_{i t}}{A_{t}}\right)^{\frac{1}{1-\alpha}}
$$

Substitute (22) and (24) into (23) and log-linearized the result, Equation (22) becomes:

$$
y_{t}=a_{t}+(1-\alpha) n_{t}
$$




\subsection{Monetary Authority}

The monetary authority (government) implements monetary policy according to a simple rule. According to the objective of this study, we compare two types of alternative monetary policy rules, which are the Taylor-type interest rate rule and money growth rate rule. The Taylor-type rule takes the form:

$$
i_{t}=\alpha_{r} i_{t-1}+\left(1-\alpha_{r}\right)\left(1+\alpha_{\pi}\right) \pi_{t}+\beta_{x}(\hat{y})+
$$

$v_{t}$

Where:

$$
\begin{aligned}
& i_{t}=\text { short term interest rate } \\
& i_{t-1}=\text { lag of short term interest rate } \\
& \pi_{t}=\text { inflation rate } \\
& y_{t}=\text { output gap } \\
& v_{t}=\text { is the monetary shock }
\end{aligned}
$$

The Money growth rate rule is similar to the Taylor-type rule. It takes the form:

$$
M_{t}=\omega_{1} M_{t-1}+\omega_{2} \pi_{t}+\omega_{3} \hat{y}+\gamma_{t}
$$

Where:

$$
\begin{aligned}
& M_{t}=\text { nominal money balance } \\
& M_{t-1}=\text { lag of nominal money balance } \\
& \pi_{t}=\text { inflation rate } \\
& y_{t}=\text { output gap } \\
& \gamma_{t}=\text { is the monetary shock }
\end{aligned}
$$

\subsection{Log-linearized model}

Log-linearization allows us to transform a system of non-linear equations into a system that is linear in terms of the log deviations of the variable around their steady-state. This operation allows for the simultaneous computation of a more tractable and cohesive system of equations, which greatly reduces computational complexity. The log-linearized systems of the above models are as follows:

$$
\begin{gathered}
y_{t}=E_{t} y_{t+1}-\sigma\left(i_{t}-E_{t} \pi_{t+1}\right) \\
\pi_{t}=\beta E_{t}\left(\pi_{t+1}\right)+k \check{y}_{t} \\
i_{t}=\alpha_{r} i_{t-1}+\left(1-\alpha_{r}\right)\left(1+\alpha_{\pi}\right) \pi_{t}+\beta_{x}(\hat{y})+v_{t} \\
M_{t}=\omega_{1} M_{t-1}+\omega_{2} \pi_{t}+\omega_{3} \hat{y}+\omega_{4} e+\gamma_{t}
\end{gathered}
$$

The first equation is called the expectational IS curve. It relates output today to its expected future value and its ex-ante real interest rate. It is obtained by subtracting the expected inflation rate from the nominal interest rate. This equation corresponds to a log-linearized 
version of the Euler equation linking an optimizing household's inter-temporal marginal rate of substitution to the real interest rate. The second equation is the New Keynesian Philip curve. The equation corresponds to a log- linearized version of the first-order condition describing optimal behaviour of monopolistically competitive firms that either face explicit costs of nominal price adjustment, as suggested by Rotemberg (1982), or set the nominal prices in a randomly staggered fashion, as suggested by Calvo (1983). The third equation is an interest rate rule for monetary policy proposed by Taylor (1993). As presented above, the central bank systematically adjusts the short-term nominal interest in response to movements in inflation. The fourth and the last equation is the money growth rate rule. It implies that the central bank sets the growth rate of nominal money balance as a function of the past growth rate of nominal money balance, inflation, exchange rate, and the output gap. The four equations involve five variables, namely nominal money balance $\left(M_{t}\right)$, output gap $\left(\mathrm{y}_{\mathrm{t}}\right)$, inflation $(\pi \mathrm{t})$, nominal exchange rate $(\mathrm{e})$, and nominal interest rate $(\mathrm{it})$.

\section{Empirical Analysis}

Estimating the DSGE model could be a herculean task if the appropriate technique is not used. Several authors (Ajemian, 2013; Akinlo and Apanisile, 2019; Apanisile and Osinubi, 2020) have favoured Bayesian estimation techniques over all other available techniques. The preference for Bayesian approach arises because of the identification problem and lack of precision that may be encountered when other techniques are used. The use of the Bayesian approach requires an initial calibration of some or all the parameters. This strategy is employed to cope with identification problems that are associated with DSGE models. One such problem emanates from the simplicity of solving small scale models relative to the difficulty of generating solutions for medium/large-scale models. Calibration in the Bayesian tradition also requires the incorporation of fixed parameters, which can be perceived as imposing a very strict prior. Essentially, the parameters defining the steady-state equilibrium are calibrated and provide the basis for assessing how far the data closely reflect the prior in the estimation process. In other words, the parameters to be calibrated should be those fundamental to achieving steady-states for the model. At the same time, they must replicate the main steady-state key ratios of the Nigerian economy not only those for which reliable estimates already exist but also those for which, an initial estimation attempt failed to yield satisfactory identification. The Bayesian method allows the incorporation of prior or theoretical knowledge, and the likelihood function through the specification of a prior distribution for the parameters to be estimated. The combination of prior and likelihood function produce the posterior distribution needed for the estimation.

\subsection{Data}

To estimate the parameters of the model, our study employed quarterly data spanning from 2000:1 to 2019:4, on seven macroeconomic indicators, namely output gap, nominal interest rate, domestic inflation rate, nominal exchange rate, nominal money balance, domestic credit to the private sector, and terms of trade. The output gap variable was computed by taking the natural log of the ratio of trend output to real output (Ajilore and Ikhide, 2013; Apanisile and Ajilore, 2013; Akinlo and Apanisile, 2019; Apanisile and Osinubi, 2020). The trend real 
output was estimated using a Hodrick-Prescott filter on the output data. The data were filtered to eliminate all sources of noise, including outliers, trend and non-stationarity in the series. This is necessary to ensure that the model converges around their steady state to determine the stability of the model. Besides, we consider two other samples for robustness check, 1995:1 -2019:4 and 2005:1 - 2019:4. We considered the former sample because it was a post liberalization period in Nigeria. The latter sample was considered because it was the period of consolidation in the banking sector.

\subsection{Estimation Technique}

Bayes' theorem defines the posterior density as:

$$
p\left(\varnothing \mid M_{1,}^{T}, Y_{i}\right)=\frac{L\left(\varnothing \mid M_{1}^{T}, Y_{i}\right) p\left(\varnothing \mid Y_{i}\right)}{p\left(M_{1}^{T} \mid Y_{i}\right)}, \text { for } i=1,2
$$

Where $\varnothing$ and $M_{1}^{T}$ denote the whole set of model parameters and the observed data, respectively. $L$ denotes the likelihood function. $p\left(\varnothing \mid Y_{1}\right)$ and $p\left(M_{1}^{T} \mid Y_{1}\right)$ are the prior density and the marginal data density conditional on $M_{i}$, respectively. $i$ represents the two models. Model 1 is for money growth rate rule, while model 2 is for Taylor-type interest rate rule. We constructed and evaluated $L\left(\varnothing \mid M_{1}^{T}, Y_{i}\right)$ by Kalman filter. We then simulate the posterior kernel, $L\left(\varnothing \mid M_{1}^{T}, Y_{i}\right) p\left(\varnothing \mid Y_{1}\right)$, for each model specification by random-walk MetropolisHastings(MH) algorithm, which is a Markov chain Monte Carlo (MCMC) simulation method commonly used in the current literature of Bayesian estimation of DSGE models. In the current literature of estimating DSGE models for Nigeria, the popular Matlab package, Dynare, is commonly used. We also estimated the model using Dynare, version 4.3.3.

To achieve the main objective of the study, which is to investigate the effectiveness of monetary policy transmission channels in Nigeria during implicit inflation targeting regime, the study developed and compared Bayesian model for the two frameworks and the most favourable model was selected based on Bayes factor. In addition, the impulse-response of the selected channels for the two models were generated. Bayes factor is defined as the ratio of marginal data densities of competing models given a unique set of data. We also estimated $\log$ marginal data density, $\log \left[p\left(M_{1}^{T} \mid Y_{i}\right)\right]$, with Geweke's (1999) modified harmonic-mean (MHM) estimator as used by Lubik and Schorfheide (2004), An and Schorfheide (2007), Traum and Yang (2011), and Li and Liu (2013).

\subsection{Calibration}

Calibration of specific parameters is referred to as priors in DSGE analysis. Priors can be garnered from personal introspection to reflect strongly held beliefs about the validity of economic theories. Priors also reflect the researcher's confidence about the likely location of the structural parameter of the model. In practice, priors are chosen based on observation, facts, and from existing empirical literature. To this end, consideration is given to the validity of the economic theory, stylized facts about the economy, observations, facts, and existing empirical literature in choosing priors for these models. Also, information from estimates of few known published studies on DSGE, using Bayesian approach, are useful in setting priors 
for most of the parameters in this exercise. The priors for the Phillips curve and the IS curve estimates were obtained from the work of Adebiyi and Mordi (2011), Mordi et. al (2013), Akinlo and Apanisile (2019), and Apanisile and Osinubi (2020). Priors of the estimated parameters and that of the standard errors of shocks are presented in tables 1 and 2.

Table 1: Priors of the Estimated Parameters for Money Growth Rule (Model 1)

\begin{tabular}{|c|c|c|c|c|}
\hline Parameter & Description & Density & Mean & Std Deviation \\
\hline$\alpha_{1}$ & $\begin{array}{l}\text { Measures impact of Inflation } \\
\text { expectation on output gap }\end{array}$ & beta & 0.300 & 0.050 \\
\hline$\alpha_{2}$ & $\begin{array}{l}\text { Measures impact of nominal } \\
\text { money balance on output gap }\end{array}$ & beta & 0.200 & 0.049 \\
\hline$\alpha_{3}$ & $\begin{array}{l}\text { Measures impact of exchange } \\
\text { rate on output gap }\end{array}$ & beta & 0.100 & 0.050 \\
\hline$\beta_{1}$ & Intercept & beta & 0.990 & 0.060 \\
\hline$\beta_{2}$ & Measures output persistence & beta & 0.125 & 0.052 \\
\hline$\beta_{3}$ & $\begin{array}{l}\text { Measures impact of Inflation } \\
\text { Expectation }\end{array}$ & beta & 0.230 & 0.050 \\
\hline$\beta_{4}$ & $\begin{array}{l}\text { Measures impact of nominal } \\
\text { money balance inflation }\end{array}$ & beta & 0.260 & 0.051 \\
\hline$\beta_{5}$ & $\begin{array}{l}\text { Measures impact of exchange } \\
\text { rate on inflation }\end{array}$ & beta & 0.150 & 0.050 \\
\hline$\varphi_{1}$ & $\begin{array}{l}\text { Measures weight put on lag of } \\
\text { money supply }\end{array}$ & gamma & 0.310 & 0.050 \\
\hline$\varphi_{2}$ & $\begin{array}{l}\text { Measures weight put on output } \\
\text { by policy makers }\end{array}$ & gamma & 0.300 & 0.054 \\
\hline$\varphi_{3}$ & $\begin{array}{l}\text { Measures weight put on } \\
\text { inflation by policy makers }\end{array}$ & gamma & 0.240 & 0.053 \\
\hline$\varphi_{4}$ & $\begin{array}{lll}\text { Measures weight put on } & \text { on } \\
\text { nominal money balance } & \text { by } \\
\text { policy makers } & & \\
\end{array}$ & gamma & 0.220 & 0.056 \\
\hline$\varphi_{5}$ & $\begin{array}{l}\text { Measures weight put on } \\
\text { exchange rate by policy makers }\end{array}$ & gamma & 0.310 & 0.050 \\
\hline eps_w & Measures terms of trade shock & invg & 0.063 & 0.0221 \\
\hline eps_x & $\begin{array}{l}\text { Measures aggregate demand } \\
\text { shock }\end{array}$ & invg & 0.488 & 0.0689 \\
\hline eps_u & $\begin{array}{l}\text { Measures aggregate supply } \\
\text { shock }\end{array}$ & invg & 0.060 & 0.0110 \\
\hline
\end{tabular}

Table 2: Priors of the Estimated Parameters for Inflation Targeting (Model 2)

\begin{tabular}{|c|l|l|l|l|}
\hline Parameter & Description & Density & Mean & Std Deviation \\
\hline$\alpha_{1}$ & $\begin{array}{l}\text { Measures impact of Inflation } \\
\text { expectation on output gap }\end{array}$ & beta & 0.300 & 0.050 \\
\hline$\alpha_{2}$ & $\begin{array}{l}\text { Measures impact of interest rate } \\
\text { on output gap }\end{array}$ & beta & 0.200 & 0.049 \\
\hline$\alpha_{3}$ & $\begin{array}{l}\text { Measures impact of exchange } \\
\text { rate on output gap }\end{array}$ & beta & 0.320 & 0.050 \\
\hline
\end{tabular}




\begin{tabular}{|c|l|l|l|l|}
\hline$\alpha_{4}$ & $\begin{array}{l}\text { Measures impact of domestic } \\
\text { credit on output gap }\end{array}$ & beta & 0.300 & 0.050 \\
\hline$\beta_{1}$ & Intercept & beta & 0.990 & 0.042 \\
\hline$\beta_{2}$ & $\begin{array}{l}\text { Measures output persistence } \\
\beta_{3}\end{array}$ & $\begin{array}{l}\text { beta } \\
\text { on inflation }\end{array}$ & 0.125 & 0.050 \\
\hline$\beta_{4}$ & $\begin{array}{l}\text { Measures impact of exchange } \\
\text { rate on inflation }\end{array}$ & beta & 0.250 & 0.050 \\
\hline$\beta_{5}$ & $\begin{array}{l}\text { Measures impact of domestic } \\
\text { credit on inflation }\end{array}$ & beta & 0.310 & 0.050 \\
\hline$\varphi_{1}$ & $\begin{array}{l}\text { Measures weight put on output } \\
\text { by policy makers }\end{array}$ & gamma & 0.300 & 0.050 \\
\hline$\varphi_{2}$ & $\begin{array}{l}\text { Measures weight put on } \\
\text { inflation by policy makers }\end{array}$ & gamma & 0.240 & 0.050 \\
\hline$\varphi_{3}$ & $\begin{array}{l}\text { Measures weight put on interest } \\
\text { rate by policy makers gamma }\end{array}$ & 0.220 & 0.056 \\
\hline$\varphi_{4}$ & $\begin{array}{l}\text { Measures weight put on } \\
\text { exchange rate by policy makers }\end{array}$ & gamma & 0.300 & 0.050 \\
\hline eps_x & $\begin{array}{l}\text { Measures aggregate demand } \\
\text { shocks }\end{array}$ & invg & 0.488 & 0.2032 \\
\hline eps_u & $\begin{array}{l}\text { Measures aggregate supply } \\
\text { shocks }\end{array}$ & invg & 0.060 & 0.0113 \\
\hline eps_w & Measures terms of trade shocks & invg & 0.063 & 0.0934 \\
\hline
\end{tabular}

The two models were simulated based on the calibration of the stochastic shocks. This process was done by filling the respective databases with the shocks' values for the starting point of the simulation. The simulation exercise is necessary to confirm whether a steady state exists and to obtain steady state values of the endogenous variables. Tables 1 and 2 showed the calibrated value of shocks as stated in the .mod file. The simulation results showed that the steady-state exists, and the steady-state values of endogenous variables were generated. Also, results of the endogenous variables' response to orthogonal shocks in both models were generated. The results are available on request.

\section{Discussion of Results}

The analytically-intractable posterior density using the Bayesian estimation technique, which combines the suitable priors with the likelihood, was obtained. To estimate the posterior, random walk $\mathrm{MH}$ algorithm was used to generate 10,000 draws from the posteriors. The study used 77 out of the available 80 data points, spanning from 2000:4 to 2019:4 for both models. For model 1, the money growth model, the log data density is -74.983519 , while the $\log$ data density for model 2 (interest rate model) is -1.086288 . Estimation results were reported in tables 3 and 4 showing the distribution used, the prior mean, the posterior mean, the prior standard deviation, and the confidence interval for the estimated parameters and standard error of shocks.

Table 3: Priors and Posterior of the Estimated Parameters for Model 1

\begin{tabular}{|c|l|l|l|l|ll|}
\hline Parameter & Density & Prior Mean & $\begin{array}{l}\text { Posterior } \\
\text { Mean }\end{array}$ & $\begin{array}{l}\text { Standard } \\
\text { Deviation }\end{array}$ & $\begin{array}{l}\text { Confidence Interval } \\
\text { at 90\% }\end{array}$ & \\
\hline$\alpha_{1}$ & beta & 0.300 & 0.3004 & 0.050 & 0.2917 & 0.3094 \\
\hline$\alpha_{2}$ & beta & 0.200 & 0.2006 & 0.050 & 0.1916 & 0.2094 \\
\hline
\end{tabular}




\begin{tabular}{|c|l|l|l|l|ll|}
\hline$\alpha_{3}$ & beta & 0.100 & 0.1000 & 0.050 & 0.0918 & 0.1077 \\
\hline$\beta_{1}$ & beta & 0.990 & 0.9906 & 0.050 & 0.9836 & 0.9975 \\
\hline$\beta_{2}$ & beta & 0.125 & 0.1248 & 0.050 & 0.1267 & 0.1334 \\
\hline$\beta_{3}$ & beta & 0.230 & 0.2297 & 0.050 & 0.2215 & 0.2386 \\
\hline$\beta_{4}$ & beta & 0.260 & 0.2587 & 0.050 & 0.2506 & 0.2677 \\
\hline$\beta_{5}$ & beta & 0.150 & 0.1499 & 0.050 & 0.1419 & 0.1686 \\
\hline$\varphi_{1}$ & gamma & 0.310 & 0.3052 & 0.050 & 0.2972 & 0.3136 \\
\hline$\varphi_{2}$ & gamma & 0.300 & 0.2989 & 0.050 & 0.2901 & 0.3064 \\
\hline$\varphi_{3}$ & gamma & 0.240 & 0.2361 & 0.050 & 0.2284 & 0.2438 \\
\hline$\varphi_{4}$ & gamma & 0.220 & 0.2097 & 0.050 & 0.2012 & 0.2180 \\
\hline$\varphi_{5}$ & gamma & 0.310 & 0.3106 & 0.050 & 0.3024 & 0.3190 \\
\hline eps_w & invg & 0.063 & 0.0425 & inf & 0.0178 & 0.0682 \\
\hline eps_x & invg & 0.488 & 1.4033 & inf & 1.2098 & 1.6003 \\
\hline eps_u & invg & 0.060 & 0.0491 & inf & 0.0156 & 0.0861 \\
\hline
\end{tabular}

Table 4: Priors and Posterior of the Estimated Parameters for Model 2

\begin{tabular}{|c|l|l|l|l|ll|}
\hline Parameter & Density & Prior Mean & $\begin{array}{l}\text { Posterior } \\
\text { Mean }\end{array}$ & $\begin{array}{l}\text { Standard } \\
\text { Deviation }\end{array}$ & $\begin{array}{l}\text { Confidence } \\
\text { at 90\% }\end{array}$ & Interval \\
\hline$\alpha_{1}$ & beta & 0.300 & 0.2950 & 0.050 & 0.2860 & 0.3040 \\
\hline$\alpha_{2}$ & beta & 0.200 & 0.1985 & 0.050 & 0.1904 & 0.2064 \\
\hline$\alpha_{3}$ & beta & 0.320 & 0.3194 & 0.050 & 0.3104 & 0.3286 \\
\hline$\alpha_{4}$ & beta & 0.300 & 0.3008 & 0.050 & 0.2917 & 0.3092 \\
\hline$\beta_{1}$ & beta & 0.990 & 0.9900 & 0.050 & 0.9825 & 0.9982 \\
\hline$\beta_{2}$ & beta & 0.125 & 0.1255 & 0.050 & 0.1170 & 0.1339 \\
\hline$\beta_{3}$ & beta & 0.260 & 0.2591 & 0.050 & 0.2508 & 0.2679 \\
\hline$\beta_{4}$ & beta & 0.250 & 0.2499 & 0.050 & 0.2413 & 0.2588 \\
\hline$\beta_{5}$ & beta & 0.310 & 0.3103 & 0.050 & 0.3021 & 0.3189 \\
\hline$\varphi_{1}$ & gamma & 0.300 & 0.2983 & 0.050 & 0.2903 & 0.3068 \\
\hline$\varphi_{2}$ & gamma & 0.240 & 0.2375 & 0.050 & 0.2293 & 0.2456 \\
\hline$\varphi_{3}$ & gamma & 0.220 & 0.2208 & 0.050 & 0.2126 & 0.2286 \\
\hline$\varphi_{4}$ & gamma & 0.300 & 0.3003 & 0.050 & 0.2918 & 0.3088 \\
\hline eps_x & invg & 0.488 & 0.3205 & inf & 0.2769 & 0.3655 \\
\hline eps_u & invg & 0.060 & 0.0468 & inf & 0.0122 & 0.0844 \\
\hline eps_w & invg & 0.063 & 0.0481 & inf & 0.0166 & 0.0850 \\
\hline
\end{tabular}

Results from tables 3 and 4 revealed that the Nigerian data is informative as the posterior means were different from the prior means. Starting with the output gap equation, the inflation expectation parameter $\left(\alpha_{1}\right)$, which is estimated to be 0.3004 in table 3 , is greater than the assumed prior mean of 0.300 . However, in table 4 , the value of the same parameter 
(0.2950) is lower than the assumed prior mean of 0.300. Also, measures of nominal money balance $\left(\alpha_{2}\right)$, estimated as 0.2006 , is higher than its assumed prior mean (0.200) while the prior and posterior means of exchange rate $\left(\alpha_{3}\right)$ are the same (0.100). In table 4 , the values of interest rate and exchange rate parameters $(0.1985$ and 0.3194$)$ are less than their assumed prior means (0.200 and 0.320). Therefore, it can be deduced from the above results that estimates obtained appear to be highly data-driven, indicating a high persistence of Nigerian households' consumption under model 1 and a relatively low persistence of households' consumption in model 2. The posteriors of the parameters of the output gap are quite distinct from the assumed priors, showing that the estimates draw important information from the data.

In the New Keynesian Phillip curve equation, the prior and posterior estimations showed that the data provide useful information explaining inflation behaviour in Nigeria. From table 3, the behaviour of the economy depends critically on the value of $\beta_{2}$ (measures of output persistence), $\beta_{4}$ (measures of nominal money balance on inflation), and $\beta_{5}$ (measures of exchange rate on inflation). The estimated value of $\beta_{4}(0.2587)$ for nominal money balance indicates the proportion of firms that do not re-optimize their prices in a given quarter. Moreover, the relatively low value of $\beta_{4}$ shows that domestic firm re-optimize prices in every two quarters. These staggered price coefficients imply that the average duration of price contracts is around two quarters. This finding is consistent with results obtained by Adebiyi and Mordi (2010) and Mordi et. al (2013). For monetary policy to impact inflation, the coefficients of the output gap and exchange rate must be greater than zero. This condition is affirmed with the coefficients of the output gap as $\left(\beta_{2}=0.1248\right)$ and the exchange rate as $\left(\beta_{5}=0.1499\right)$. This finding provides the $\mathrm{CBN}$ an important tool to control inflation through output gap. Also, the impact of the exchange rate on prices indicates that the exchange rate pass-through into consumer prices is 14 per cent, which is very high. From table 4 , the behaviour of the economy depends critically on the value of $\beta_{2}$ (measures of output gap expectation), $\beta_{3}$ (measures of interest rate on inflation), and $\beta_{4}$ (measures of exchange rate on inflation). The estimated value of $\beta_{3}(0.2591)$ for interest rate indicates the proportion of firms that do not re-optimize their prices in a given quarter. This also implies domestic firms re-optimize their prices in every two quarters. For model 2, the coefficients of the output gap and exchange rate $(0.1255$ and 0.2499$)$ are greater than zero. This provides an important tool for CBN to control inflation through the output gap. Also, the impact of the exchange rate on prices indicates that the exchange rate pass-through into consumer prices is 24 per cent, which is relatively high.

The posterior estimates of the Central Bank of Nigeria's monetary policy reaction function provide a reasonable description of monetary policy design during the study period. The overall results of the reaction functions show the effectiveness of monetary policy design in Nigeria with price stability as its primary objective. With regards to the persistence of the estimated standard deviations, the most volatile shock considered in the two models is the aggregate demand shock (1.4033) in model 1 and 0.3205 in model 2 . In contrast, the least volatile is terms of trade shock (0.0425) in model 1 and aggregate supply shock (0.0468) in 
model 2. For most of these parameters, results seem to be driven to a reasonable extent by the data.

Figures 1 and 2 show the prior and posterior distribution of the parameters. The diagram combines the prior (grey) and posterior (black) distributions for the parameters of the models. The vertical green line in each chart identifies the posterior mode from the numerical optimization simulations. The optimization mode is usually similar to the posterior mode, with only a few exceptions. By implication, both the data and the selected priors are informative about the parameters, which help to substantiate the probability of our estimates. Also, the prior and posterior distributions are fairly close. The diagram also shows that the plotted posterior distributions do not appear to deviate substantially from normality, showing that the model perfectly fits the Nigerian economy.
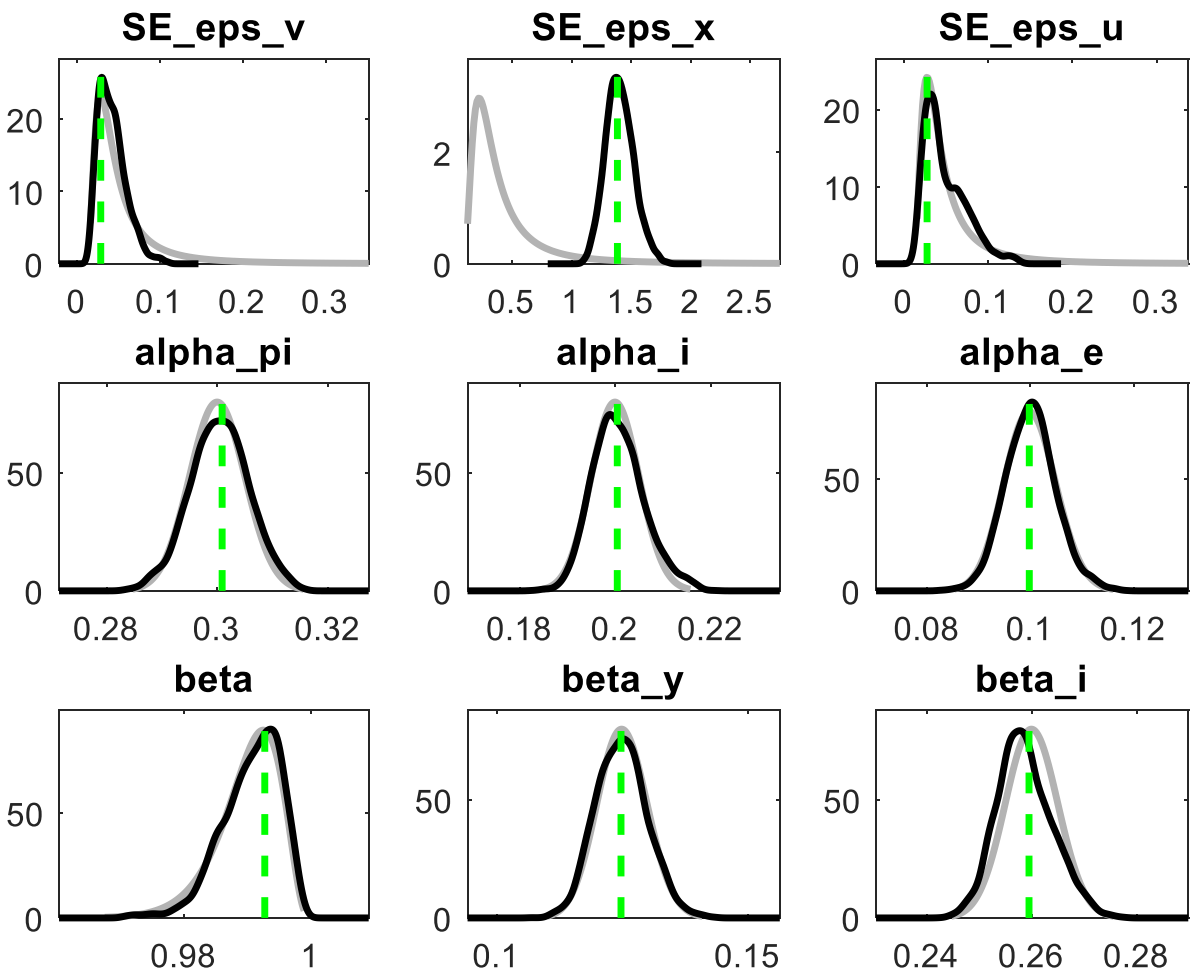

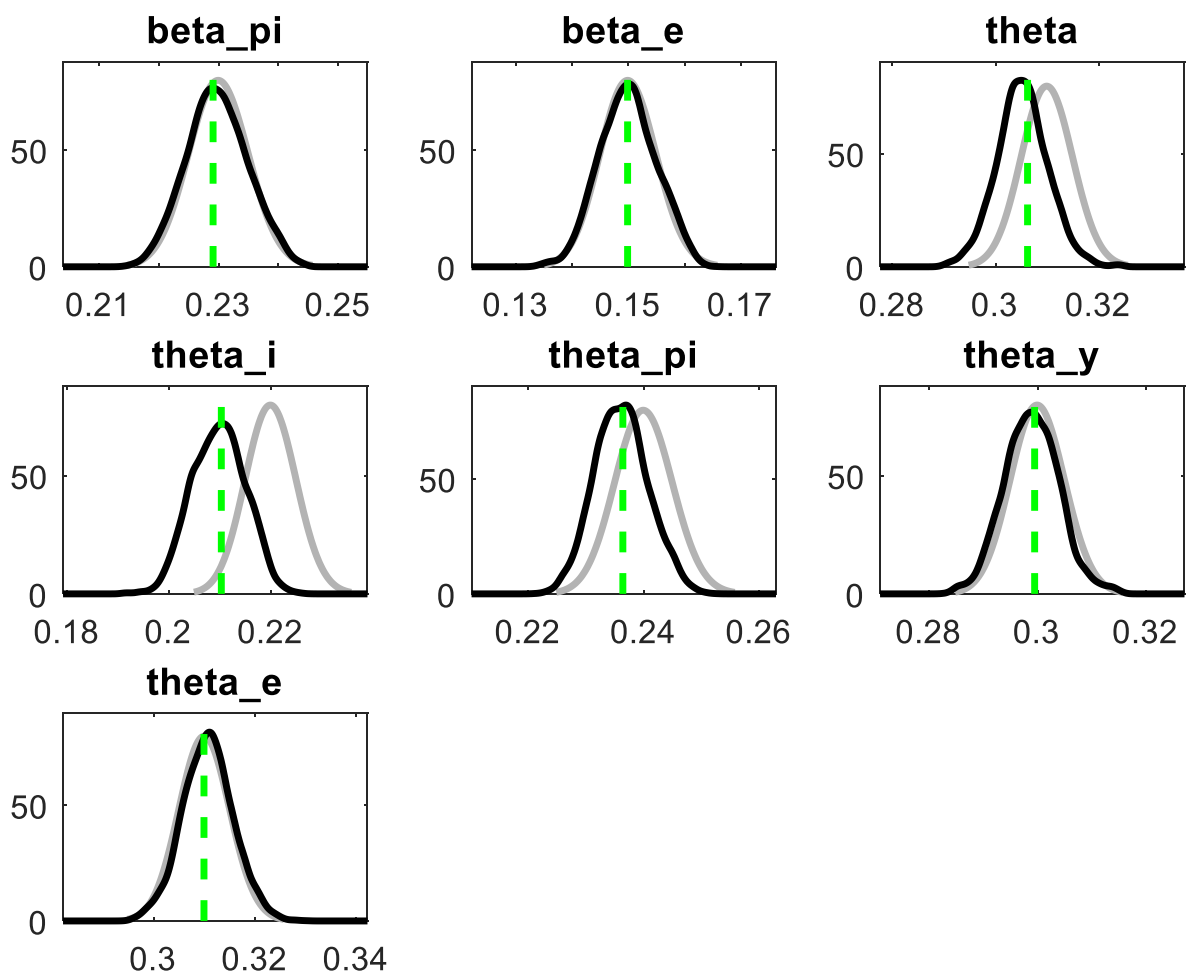

Figure 1: Prior and Posterior Distribution for Model 1 

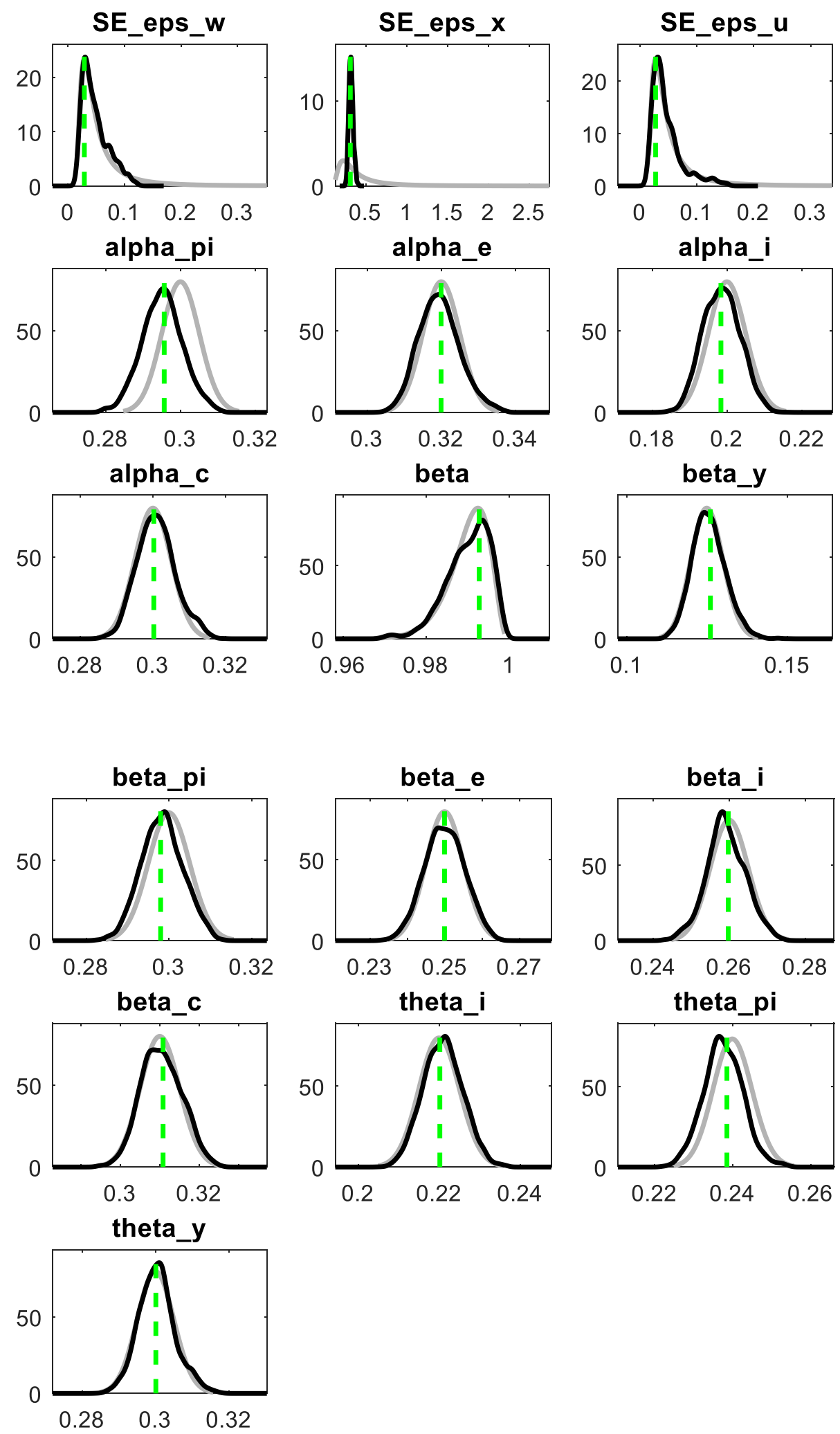

Figure 2: Prior and Posterior Distribution for Model 2

\subsection{Viability of the Estimation}


Statistical integrity of the Bayesian estimation procedures is tested, and the result examined using a set of visual diagnostic tests for the two models. The sensibility of the MetropolisHastings simulations was investigated using the univariate and multivariate Monte Carlo Markov Chain (MCMC) diagnostic test. The sensibility of the $\mathrm{MH}$ algorithm requires that the simulations are similar within and across the chains. Both lines should display little variability and eventually converge (Griffoli, 2007; Modi et al. 2013). The diagrams are generated and results show that the moments for all the parameters of the model seem stable and converge smoothly. The results are available on request.

As for the MH sampling algorithm, a diagnosis of the overall convergence is summarized in three graphs. Each graph represents specific convergence measures with two distinct lines that represent the results within and between chains. Those measures are related to the analysis of the parameters mean (interval), variance (m2) and third moment (m3). Convergence requires that both lines, for each of the three measures, become relatively constant and converge to each other. The charts were generated and result supports the stability and convergence of the MH solver for all the models as both lines of the diagrams converge at the tail end of the diagram. Results are also available on request.

\section{2: Model Comparisons}

Table 5: Model Comparisons

\begin{tabular}{|c|c|c|c|}
\hline Sample & Specification & $\log \left[\boldsymbol{p}\left(\boldsymbol{Y}_{\mathbf{1}}^{\boldsymbol{T}} \mid \boldsymbol{M}_{\boldsymbol{i}}\right)\right]$ & Bayes Factor Versus M2 \\
\hline 1995:1-2019:4 & M1 & -110 & $\exp (98)$ \\
& M2 & -12 & 1 \\
\hline 2000:1 - 2014:4 & M1 & -74 & $\exp (66)$ \\
& M2 & -8 & 1 \\
\hline 2005:1-2014:4. & M1 & -13 & $\exp (8)$ \\
& M2 & -5 & 1 \\
\hline
\end{tabular}

Given the peculiarity of implementation of monetary policy in Nigeria in which inflation targeting framework is implicit with the monetary aggregate explicit, it becomes imperative to make a comparison based on data availability and know which of the two models is effective. In table 5, we report the log densities and the Bayes factors for the baseline sample and the two other samples for robustness check. For the baseline sample, the log data density under M1 is -74 , and that of M2 is -8 . Hence, the Bayes factor of M2 versus M1 is $\exp (66)$, which is a strong indication that M2 is favoured by the data. This is robust as shown from the results for the other two samples. Therefore, we argue that analyzing Nigeria's monetary policy by building DSGE models with inflation targeting framework is a more reasonable choice even with its implicit nature in Nigeria.

\section{3: Bayesian Impulse Response}


This section examined the responses of monetary policy transmission channels to shocks during the monetary aggregate framework (M1) and the implicit inflation targeting framework in Nigeria. The Bayesian impulse responses are presented with their respective graphical representation in Figures 3 - 8.
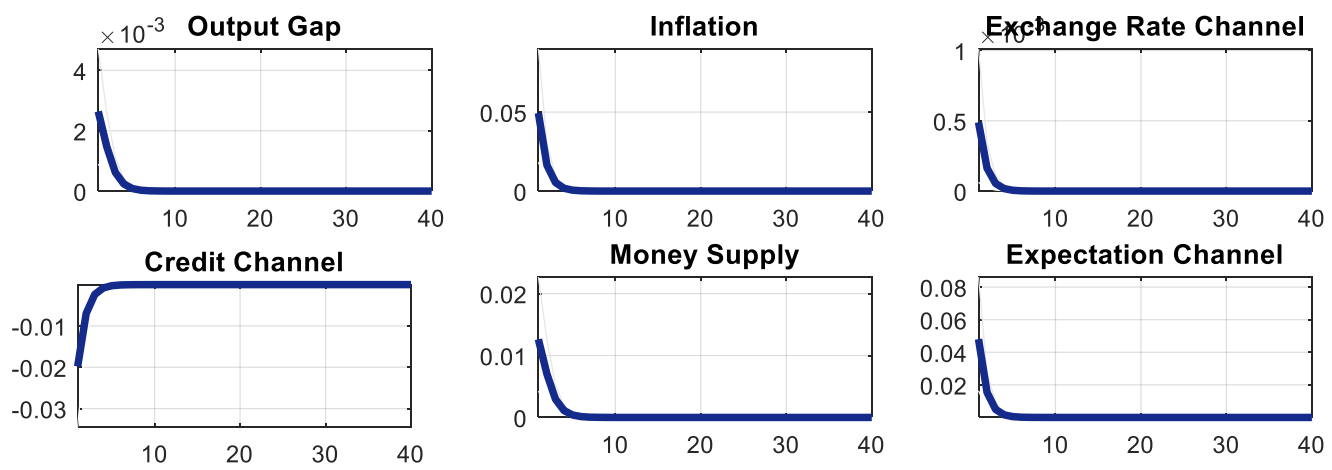

Figure 3: Response to $1 \%$ aggregate supply shock for model 1

Channels of monetary policy transmission differ in their response to an aggregate supply shock. Exchange rate channel, expectation channel, and money supply responded negatively to aggregate supply shock as the value of impulses transmitted to the economy fell. Output and inflation also responded in the same manner as their values fell. By implication, aggregate supply shock reduces both output and inflation. However, the credit channel responded positively as the value of impulse transmitted increases. Given that supply shock led to temporal supply adjustment problems, it reduced output, inflation, and people's expectation in all the quarters. The variables eventually converged to their steady-state in the long run. 

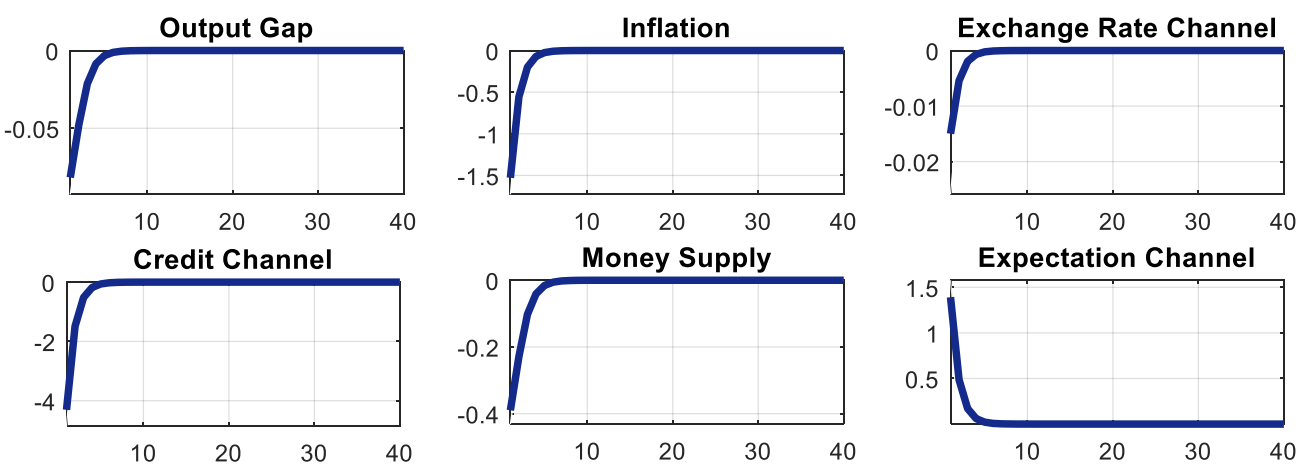

\section{Figure 4: Response to 1\% aggregate demand shock for model 1}

Aggregate demand shock could either be positive or negative. A positive aggregate demand shock could be in the form of an increase in government expenditure or a cut in taxes. In contrast, a negative aggregate demand shock is the opposite of the positive shock. A positive one per cent shock to aggregate demand impacted positively on all the variables except the expectation channel. This finding shows that aggregate demand shock increases output, exchange rate, credit, money supply and inflation. All variables return to their steady states in the long run.
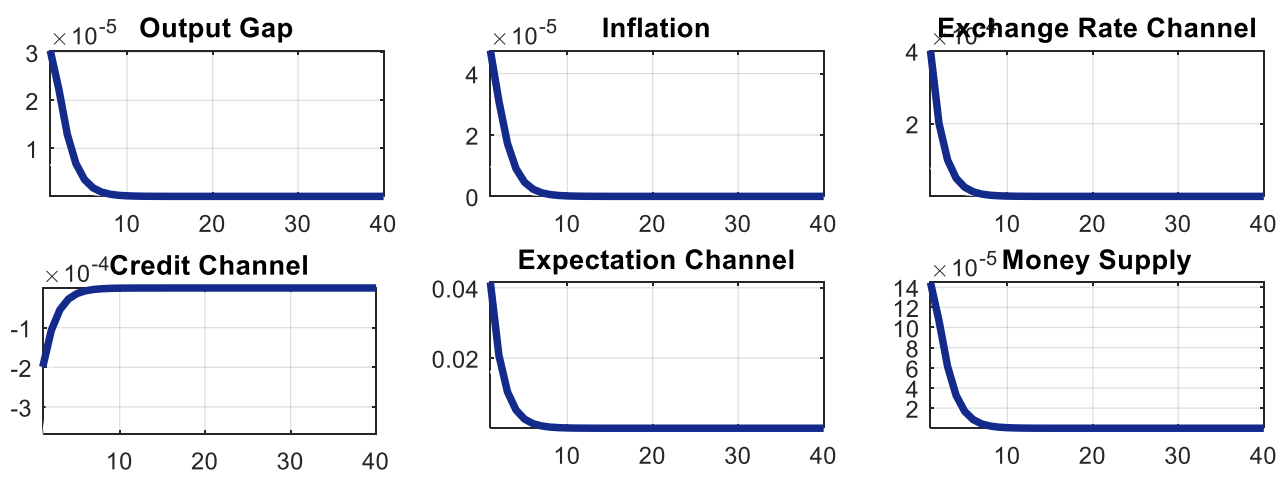

Figure 5: Response to $1 \%$ terms of trade shock for model 1 
The effect of terms of trade shock under the monetary targeting framework is similar to that of an aggregate supply shock. A $1 \%$ terms of trade shock negatively impacted on all the variables, as evident in figure 5, except the credit channel. It reduces output and inflation in the economy during the period under study. However, the credit channel responded positively as the magnitude of shock transmitted increases throughout the period. The results remained the same both in the short-run and long-run periods.
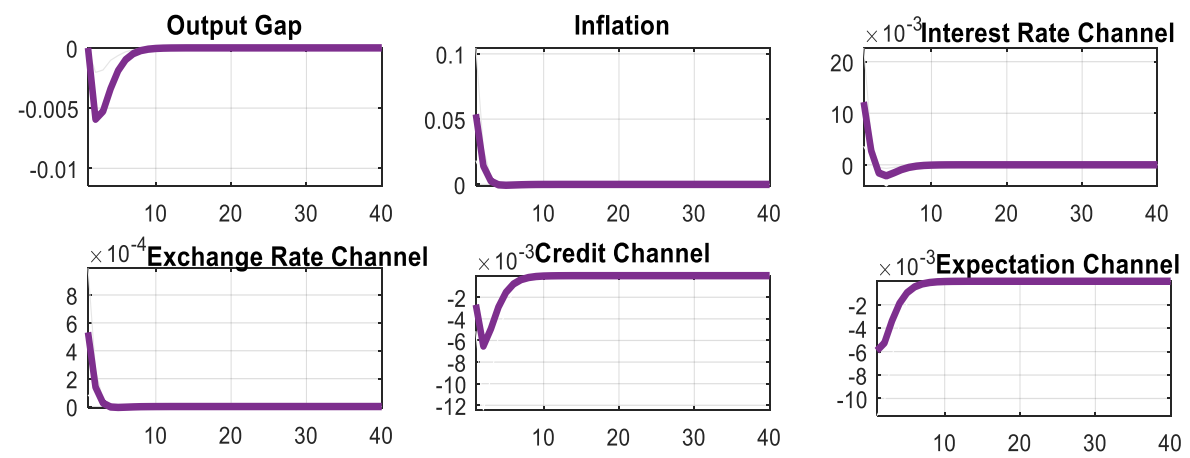

Figure 6: Response to $1 \%$ aggregate supply shock for model 2

The response of variables to aggregate supply shock under implicit inflation targeting is quite different from that of monetary targeting framework. Under implicit inflation targeting, a $1 \%$ aggregate supply shock increases output, credit, and expectation channels. However, it reduces inflation, interest rate, and exchange rate in all the periods. The variables eventually converged to their steady-state in the long run.
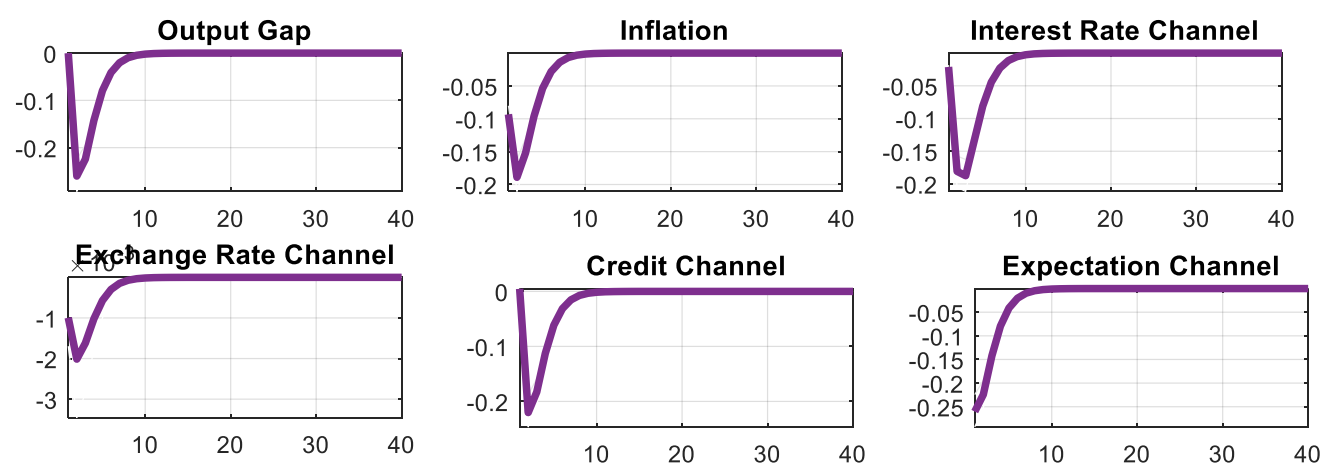


\section{Figure 7: Response to 1\% aggregate demand shock for model 2}

A positive $1 \%$ aggregate demand shock has a positive impact on all the variables. In the short-run, it has a negative effect, which increased in the medium and long-run periods. All variables later return to their steady states. This implies that aggregate demand shock reduced output, inflation, interest rate, exchange rate, and credit to the private sector in the short-run and later increased. However, the case of people's expectation is different. It increased throughout the periods, both in the short-run and long-run.
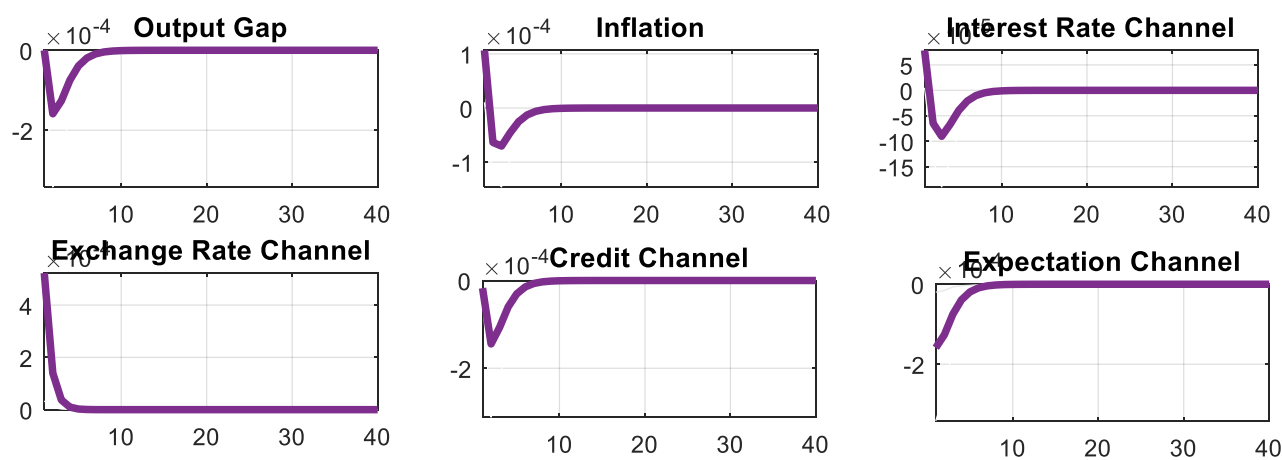

Figure 8: Response to $1 \%$ terms of trade shock for model 2

A $1 \%$ positive terms of trade shock has a positive impact on all the variables except the exchange rate. The pattern of its impact differs among the variables. For example, people's expectation responded positively both in the short and long-run periods. However, the terms of trade has a negative impact on output gap, inflation, interest rate, and credit to the private sector in the short-run. The reverse is the case in the long-run. However, exchange rate responded negatively to terms of trade shock both in short and long-run. All variables converged to their equilibrium levels.

In sum, comparing the responses of the four transmission channels considered in the study for both models, one can say that the channels performed better under implicit inflation targeting regime than monetary targeting regime. However, the responses of the transmission channels to aggregate demand shock for the two regimes are similar. This implies that effects of aggregate demand shock are persistent under the two models. The results show that monetary policy transmission channels are more active and performed better under implicit inflation targeting. The only obstacle to its operation is the implicit nature of its implementation in the country. 


\subsection{Conclusion}

The study examines the performance of the monetary policy transmission mechanism in the country in the face of implicit inflation targeting regime using quarterly data from 2000:1 to 2019:4. Specifically, the study estimated a sticky-price DSGE model using the Bayesian estimation approach. The study is important because a sound understanding of the extent to which monetary policy impulses are transmitted to the economy is a critical element in determining the performance of monetary policy in achievement of set macroeconomic objectives. The results show that the inflation targeting framework is strongly favoured by the data relative to the monetary targeting framework. Besides, the transmission mechanism performs better in the face of implicit inflation targeting regime. However, its impact was dampened by the effect of monetary targeting that was made explicit. By implication, the country might not benefit from the opportunities provided by inflation targeting regime in achieving price stability if the framework is not explicit. The study concluded that for the country to achieve the primary objective of price stability, inflation targeting should be made explicit and that Central Bank of Nigeria should stick to one policy framework rather than the hybrid that is in place.

\section{References}

Adebiyi Micheal A. and Mordi Charles O. (2011): "Building Dynamic Stochastic General Equilibrium Models for Monetary Policy Analysis". CBN Economic and Financial Review 49(1):1-24

Adjemian S (2013): "Bayesian Estimation of DSGE models". Universite du Maine, GAINS \& CEPREMAP, January 24, 2013.

Ajilore, T. and Ikhide, S. (2013): "Monetary Policy Shocks, Output and Prices in South Africa: A Test of Policy Irrelevance Proposition". Journal of Developing Areas, 42(2):363-386.

Akinlo, A. E., \& Apanisile, O. T. (2018). Monetary policy shocks and effectiveness of channels of transmission in Nigeria: A Dynamic Stochastic General Equilibrium (DSGE) approach. Global Business Review, 20(2), 331-353.

Akyurek, C., Kutan, A., M., and Yilmazkuday, H. (2011). "Can Inflation Targeting Regimes be Effective in Developing Countries? The Turkish Experience". Journal of Asian Economics, 22(1): 343-355.

Amar A. B., Hachicha, N,. and Saadallah, R. (2015). "The Effectiveness of Monetary Policy Transmission Channels in the Presence of Islamic Banks: The Case of Saudi Arabia”. International Journal of Business, 20(3): 237-259.

An, S., and F. Schorfheide (2007): "Bayesian Analysis of DSGE Models (with discussion)." Econometric Reviews, 26(2-4), 113-219.

Apanisile, O., T. and Ajilore, T. (2013): "Inflation Targeting Monetary Policy Rule in Nigeria: Estimates of the Policy Reaction Function" International Journal of Economics and Finance, 5(7): 139-144.

Apanisile, O. T., and Osinubi, T. T. (2020). "Financial Development and the Effectiveness of Monetary Policy Channels in Nigeria: A DSGE Approach". Journal of African Business, 21(2): 193-214.

Awad, I., L. (2011). "The Monetary Transmission Mechanism in a Small Open Economy: The Case of Egypt. Journal of Economics and Business 14(1):73-96. 
Calvo, G.A. (1983). "Staggered Prices in a Utility-Maximizing Framework", Journal of Monetary Economics, 12(1): 383-398.

Can, U., Bocuoglu, M., E., and G., Z., Can (2020). "How does the monetary transmission mechanism work? Evidence from Turkey". Borsa Istanbul Review, https://doi.org/ 10.1016/j.bir.2020.05.004.

CBN (2017). Central Bank of Nigeria Annual Reports, 2017.

CBN (2019). Central Bank of Nigeria Statistical Bulletin, 2019.

Cevik, S., and Teksoz, K. (2012). "Lost in Transmission? The Effectiveness of Monetary Policy Transmission Channels in the GCC Countries". Middle-East Development Journal, 5(3): 1350018-1-1350018-21.

Fuddin, M. (2014). "Effectiveness of Monetary Policy Transmission in Indonesia". Economic Journal of Emerging Markets, 6(2):119-130.

Griffoli, T. M. (2007). DYNARE user manual: An introduction to the solution and estimation of DSGE models. Unpublished Manuscript.

Jain-Chandra, S., and Unsa, D., F. (2014). "The effectiveness of monetary policy transmission under capital inflows: Evidence from Asia". Borsa Istanbul Review, 14(1): 96-103.

Li, B., and Liu, Q. (2017). "Identifying Monetary Policy Behaviour in China: A Bayesian DSGE approach". China Economic Review, 44(1): 166-185.

Lubik, T.A., and F. Schorfheide (2004): "Testing for Indeterminacy: An Application to U.S. Monetary Policy." American Economic Review, 94(1), 190-217.

Mordi Charles et. al.(2013): "Dynamic Stochastic General Equilibrium Model for Monetary Policy Analysis in Nigeria". Research Department, Central Bank of Nigeria.

Ogun, T. P., \& Akinlo, A. E. (2010). The effectiveness of bank credit channel of monetary policy transmission: The Nigerian experience. African Economic and Business Review, 8(2), 15-29.

Otolorin, G., E and Akpan, P., E. (2017). "Effectiveness of Monetary Policy Transmission Channels in a Recessed Economy". Uyo Journal of Sustainable Development, 2(2): 80-100.

Patrick, C. M., and Akanbi, O. A. (2017). "The Relative Importance of the Channels of Monetary Policy Transmission in a Developing Country: The Case of Zambia". African Journal of Economic Review 5(2): 149-174.

Peiris, S. J. and Saxegaard, M. (2007) "An Estimated DSGE Model for Monetary Policy Analysis in low-income Countries", IMF Working Paper WP/07/282.

Ripdian N, M., Hayati, B., and Yusuf A. G. (2018). "Effectiveness of Monetary Policy Transmission Mechanism in Indonesia". Jurnal Ekonomi dan Kebijakan, 11 (1): 189-206.

Rotemberg, J.J. (1982). "Sticky Prices in the United States". Journal of Political Economy 90(1): $1187-1211$.

Taylor, J.B. (1993): "Discretion versus Policy Rules in Practice.” Carnegie-Rochester Conference Series on Public Policy, 39, 195-214.

Zholuda, O., Lepushynskyia, V., and Nikolaychuka, S. (2011). "The Effectiveness of the Monetary Transmission Mechanism in Ukraine since the Transition to Inflation Targeting". Visnyk of the National Bank of Ukraine, No. 247, pp. 19-37 
Figures
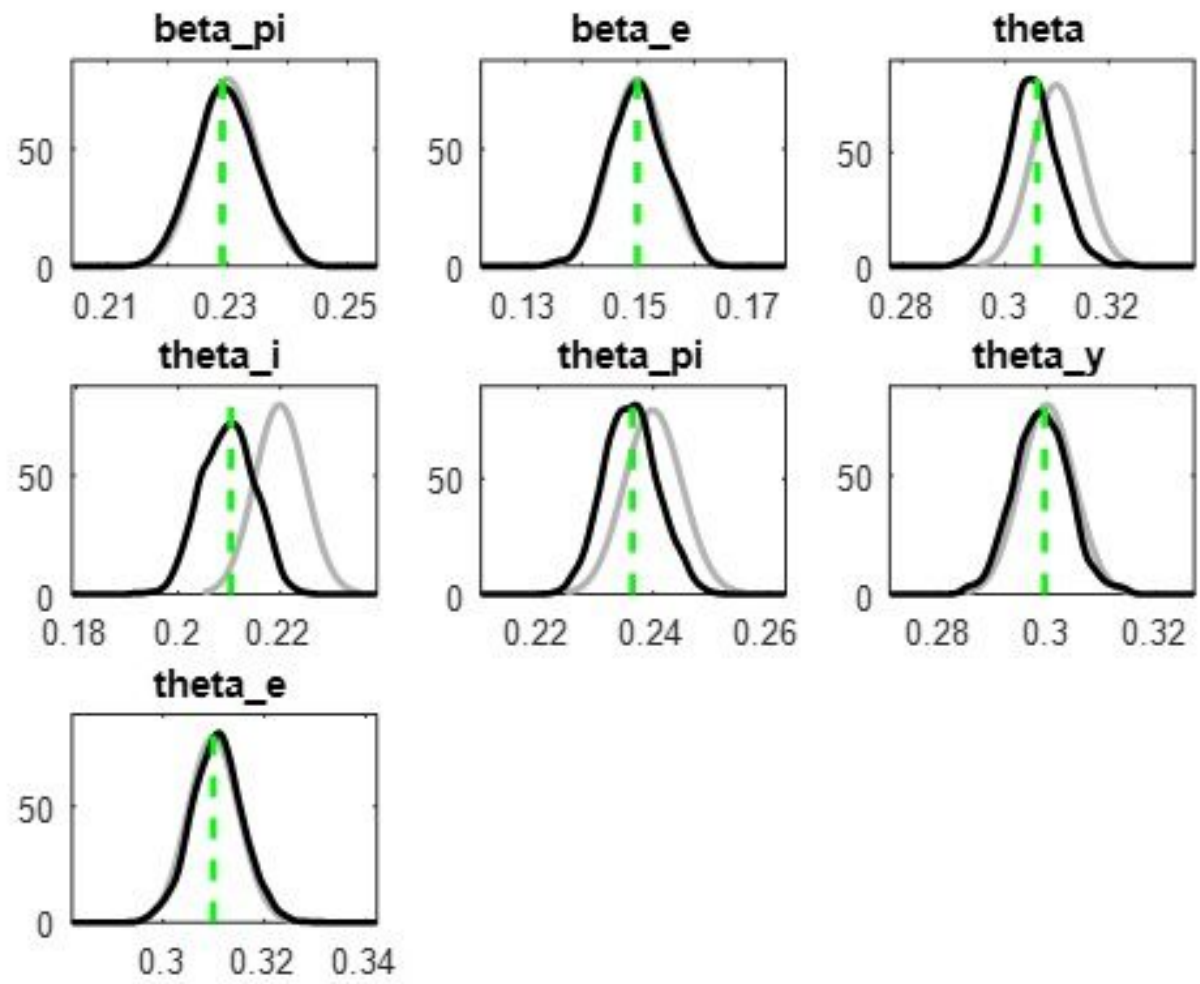

Figure 1

Prior and Posterior Distribution for Model 1 

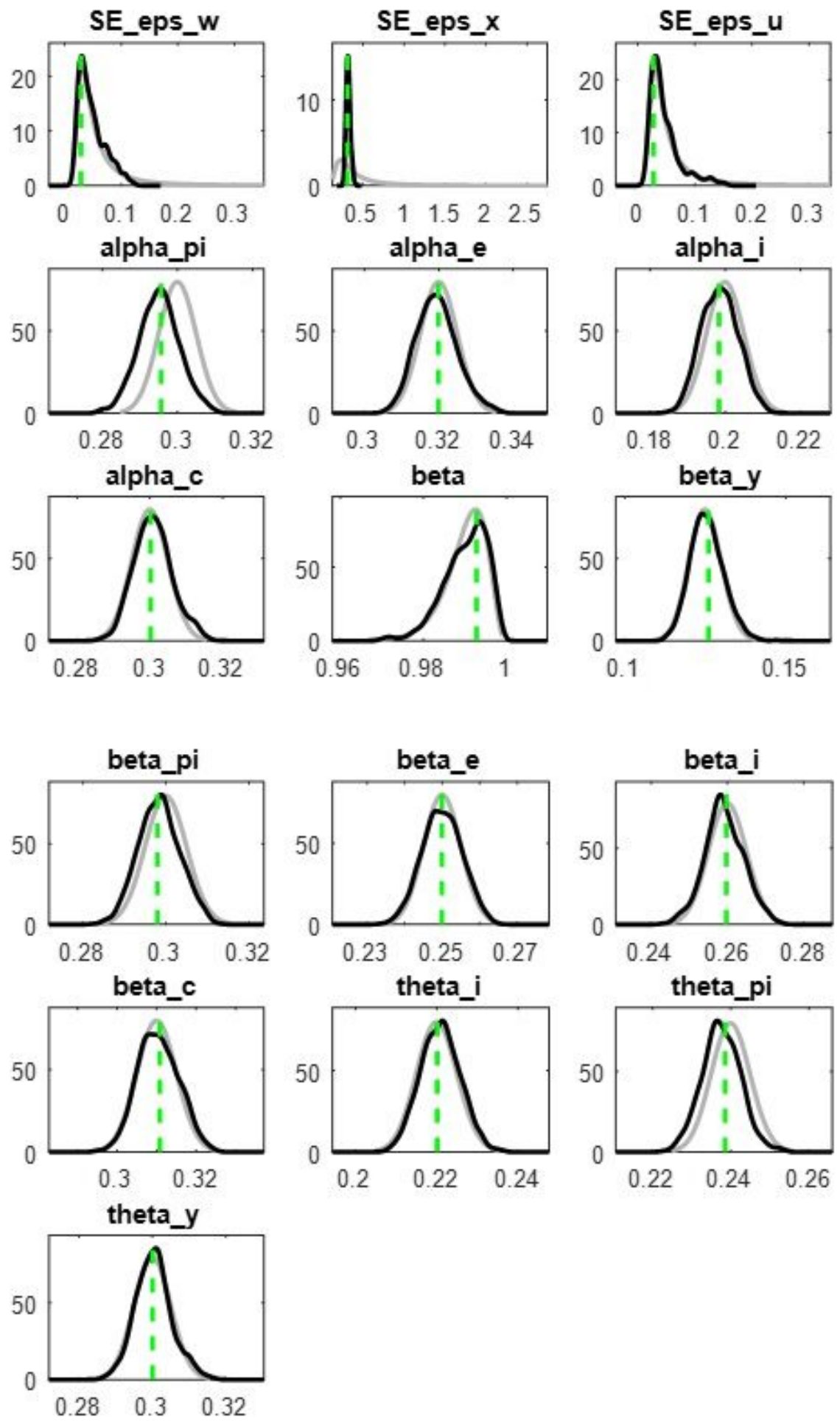

\section{Figure 2}

Prior and Posterior Distribution for Model 2 

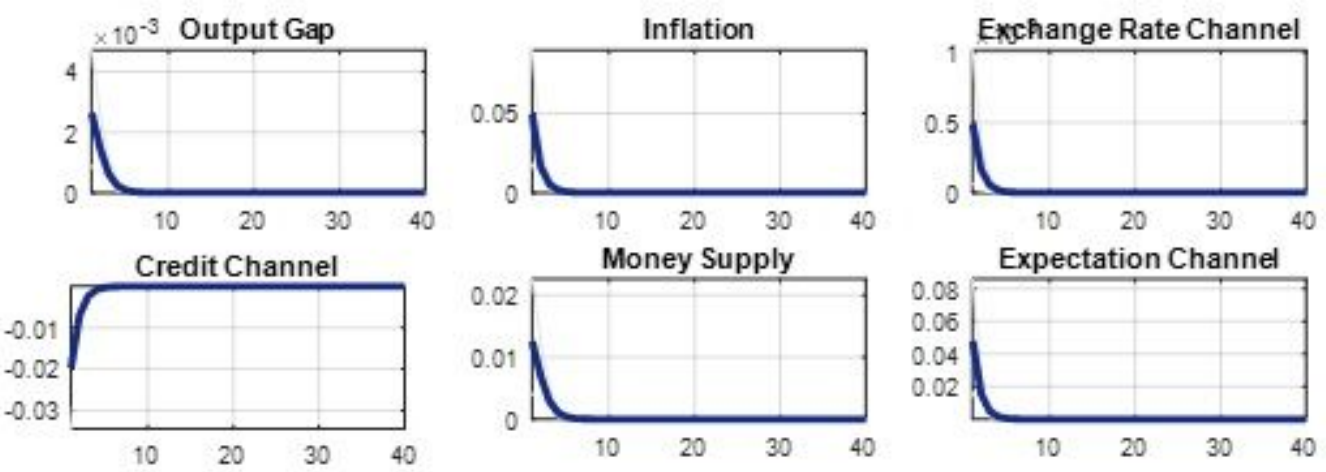

\section{Figure 3}

Response to $1 \%$ aggregate supply shock for model 1
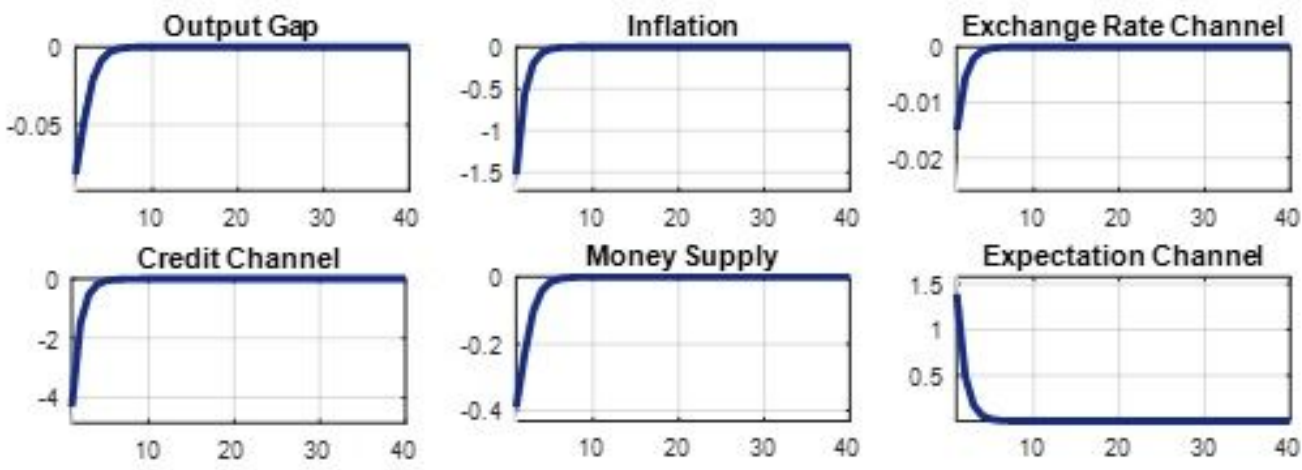

\section{Figure 4}

Response to $1 \%$ aggregate demand shock for model 1
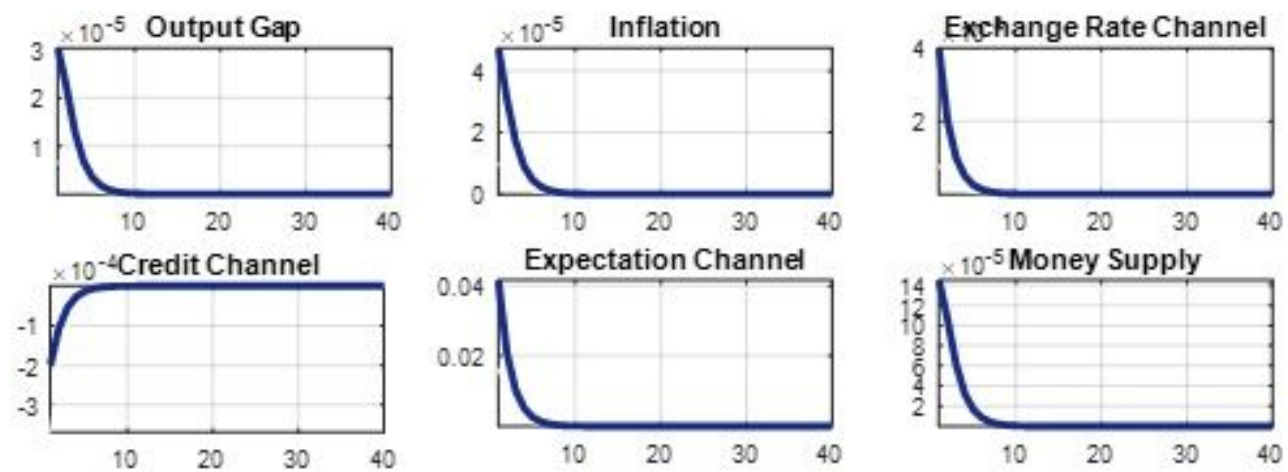

Figure 5

Response to $1 \%$ terms of trade shock for model 1 

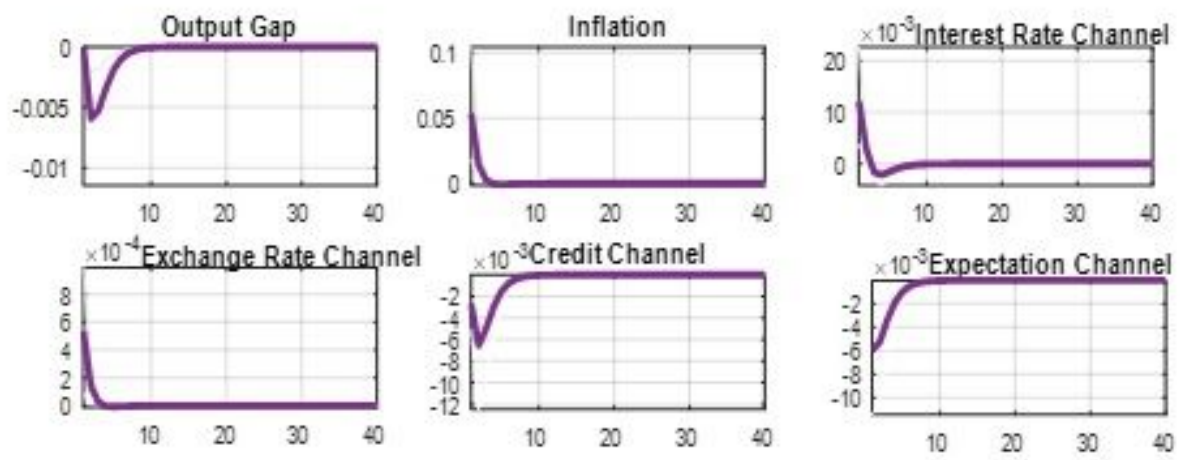

\section{Figure 6}

Response to $1 \%$ aggregate supply shock for model 2
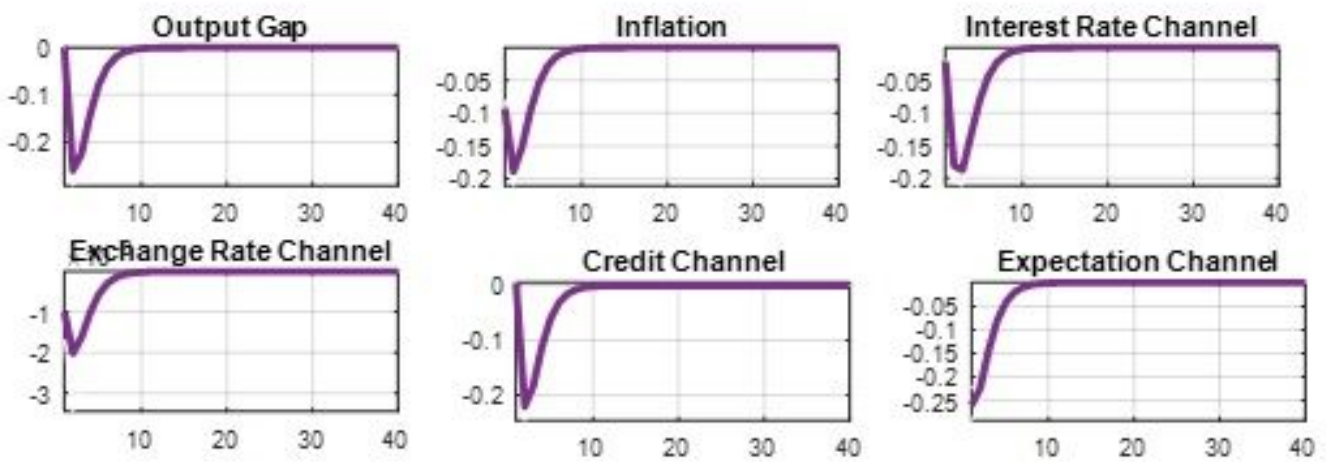

\section{Figure 7}

Response to $1 \%$ aggregate demand shock for model 2
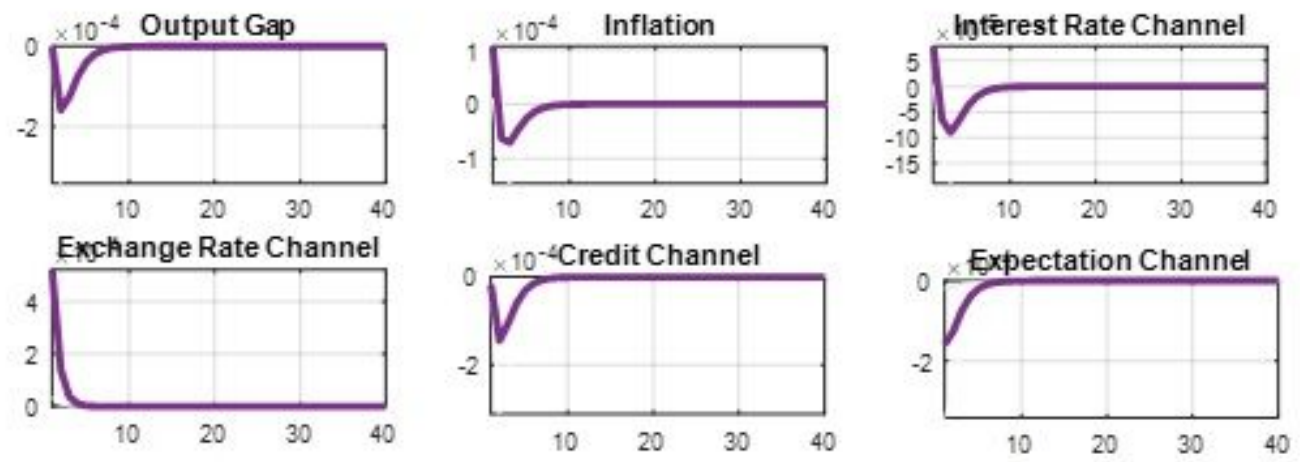

Figure 8

Response to $1 \%$ terms of trade shock for model 2 